\title{
PERSISTANT GENITAL AROUSAL DISORDER IN ELDERLY WOMEN: A CASE STUDY
}

\author{
Mariana Arnaoudova \\ Department of psychiatry, Medical University - Varna; Third psychiatric Clinic, \\ University Hospital "St. Marina” - Varna, Bulgaria
}

\section{SUMMARY}

Persistent genital arousal (PGAD) is an unusual, rarely diagnosed but a real problem for some women which causes considerable physical and psychological distress. It is characterized by physiological signs of sexual arousal that persist despite the absence of sexual desire. A number of theories have been proposed and various psychological and medical treatments have been used to treat this condition with varying success.

The problem is even more serious with elderly women. In our clinical practice we have met a number of patients with such complains, which we have discussed mostly in terms of depression, panic disorder or SSRI's application.

In our paper we discuss some diagnostic and therapeutic issues and present a case of a 71 years old woman, who experienced distinct symptoms of PGAD for nearly 10 years. She was treated with a number of antidepressants and benzodiazepines without effect. Olanzapine $5 \mathrm{mg}$ at bed time was administered. A good therapeutic response was achieved from the same evening and was held at the hospital stay and afterwards.

Key words: PGAD, diagnosis, treatment

\section{INTRODUCTION}

Persistent genital arousal disorder (PGAD) describes the experience of persistent feelings of genital arousal that is not caused by sexual stimulation and is not experienced as sexual pleasure. These feelings can last for hours or days and can cause extreme distress and discomfort to the person experiencing PGAD. It is a newly described disorder that is not yet fully understood. It was firstly characterized and called Persistent Sexual Arousal Syndrome (PSAS) by Leiblum and Nathan in 2001. Women with PSAS experienced excessive and persistent arousal, instead of little to no arousal. In none of the cases described, any hormonal, vascular, neurological, psychological or anatomic abnormalities were found $(1,2,3)$. Some physicians use the term Persistent Sexual Arousal Syndrome (PSAS) to refer to the condition in women; others consider the syndrome of priapism in men to be the same disorder. In particular, it is not related to hyper-sexuality sometimes known as nymphomania or satyriasis. That's why at 2007 Leiblum changed the name of the condition to
Persistent Genital Arousal Disorder (PGAD) pointing out the problem is not to be a sexual problem per se but rather a problem of unremitting genital sensations (4). Research is only in the earliest stages. Goldmeier et al. (2009) underline on the lack of knowledge about this newly recognized condition (5). Leiblum et al. (2007) hypothesized that for a subset of women, psychological factors, namely anxiety, reinforce exacerbate and maintain PGAD (6). A number of theories regarding causes and pathophysiology have been proposed and various psychological and medical treatments have been used to treat this condition with varying success. Brotto et al. (2010) comment the urgent need for more data on the assessment, etiology, and treatment of PGAD (7). Withdrawal of SSRI's is discussed as a reason for persistent sexual arousal in women (8) or medical, pharmacological, vascular, and neurological factors $(6,9,10)$.

In our paper we discuss some diagnostic and therapeutic issues and present a case of 71-year old woman who was experiencing symptoms, associated with PGAD for nearly 10 years. She was admitted at geronto-psychiatric department with diagnosis of depression. Clinical examination revealed no symptoms of depression, cognitive deficit or other mental illness. She looked tense, embarrassed and desperate. Gradually she relaxed and described in details her complaints. Last 10 years, she had experienced recurrent episodes, approximately several times a week, in which she would 5 to 10 minutes after lying in bed, primary at the evening or in the afternoon, began to feel relaxed and "lighter", hot flashes, pulsations and pressure in the pelvic area were following next. She describes feelings similar to sexual arousal and orgasm, lasting for average two hours, not caused by sexual stimulation and not experienced as sexual pleasure. She feels extremely distressed. She has tried a number of psychotropic drugs, mostly antidepressants and bezodiazepines but their usage worsened her condition. Based on drug history of poor therapeutic response of antidepressants, mood stabilizers and some atypical antipsychotics, $5 \mathrm{mg}$ Olanzapine was administered at bed time. A good therapeutic response was achieved from the same evening and was held at the hospital stay and later on. She did not consent for other examinations, being happy "to find her drug". 


\section{DISCUSSION}

We don't have experience in diagnosing of PGAD because we are dealing with elderly patients and they usually don't speak about sexual problems. In our clinical practice we have met a number of patients with such complaints, which we have discussed mostly in terms of depression, anxiety, panic disorder or SSRI's application. It is our first documented detailed description of symptoms, associated with PGAD, based on: a). Experiencing physiological response similar to sexual arousal that lasts for an extended period of time (from hours to days) and does not go away on its own; b). Physical signs are not related to feeling sexually excited or sexual desire; c). Physical experience may be triggered by nonsexual events or by nothing at all; d). Physical signs of arousal do not go away after orgasm, or may require multiple orgasms to go away; e). The experience is considered intrusive and unwanted; and when it persists, can create significant distress (4).

To our knowledge, there is little and not reliable data on the prevalence of PGAD. It's possible that the disorder is more common than researches think it is. On one hand the disorder is being very rare, on the other- the condition is frequently unreported by sufferers who may consider it embarrassing. Leiblum (2006) postulated that there may be two subtypes of PGAD: one more closely related to physiological factors (e.g., neurovascular or neurochemical), and the other to psychological factors (3). Several hypotheses have been summarized as: central neurological changes (e.g., post-surgical, post-injury brain lesion, seizure disorder), peripheral neurological changes (e.g., pelvic nerve hypersensitivity or entrapment), vascular changes (e.g., pelvic congestion or dilatation, or vascular pathology associated with chronic fatigue syndrome, mechanical pressure against genital structures, medication-induced changes (e.g. upon either initiation or cessation of SSRI or mood stabilizer therapy), psychological factors, (e.g. severe stress, the perception and persistence of symptoms, anxiety and obsessive vigilance about physical symptoms, overall lower levels of sexual satisfaction, lower desire and greater pain), beginning menopause, physical inactivity $(4,11,12)$. According to Guiliano et al. (2011) an important issue to be investigated is the role of neurotransmitters involved in the control of genital sexual arousal (13).

Treatment may be considered psychologic and biologic. No single medications are recommended due to the lack of clear understanding of the etiology and mechanisms underlying PGAD. Pharmacologic strategies have included use of antidepressants (14), olanzapine, risperidone, antiseizure medications (e.g. carbamazepine), use of the opioid agonist tramadol, and use of varenicline (a partial agonist at the nicotinic receptor subtype that decreases the ability of nicotine to stimulate the release of mesolimbic dopamine)(15). Although the proposed treatments do not completely eliminate the condition, they may help reduce pain, stress, and discomfort. Multidimensional approach is suitable as various factors have been implied.

\section{CONCLUSION}

In terms of the case of PGAD that we describe further research mostly in direction of understanding the role of the CNS neuroendocrine and neurotransmitter system in modulating sexual behavior is warrant.

\section{REFERENCES:}

1. Leiblum SR, Nathan SG. Persistent sexual arousal syndrome: A newly discovered pattern of female sexuality. $J$ Sex Marital Ther. 2001 JulSep;27(4):365-80. [CrossRef] [PubMed]

2. Leiblum SR, Nathan S. Persistent sexual arousal syndrome in women: A not uncommon but little recognized complaint. Sex Rel Ther 2002; 17:191198.

3. Leiblum SR. Arousal disorders in women: complaints and complexities. Med J Aust. 2003 Jun 16; 178(12):63840. [PubMed]

4. Leiblum SR. Persistent genital arousal disorder: What it is and what it isn't. Contemporary Sexuality, July 2006.

5. Goldmeier D, Mears A, Hiller J,
Crowley T; BASHH Special Interest Group for Sexual Dysfunction. Persistent genital arousal disorder: A review of the literature and recommendation for management. Int $J$ STD AIDS. 2009 Jun; 20(6):373-7. [CrossRef], [PubMed]

6. Leiblum S, Seehuus M, Goldmeier D, Brown C. Psychological, Medical, and Pharmacological Correlates of Persistent Genital Arousal Disorder. $J$ Sex Med. 2007 Sep;4(5):1358-66. [PubMed] [CrossRef]

7. Brotto LA, Bitzer J, Laan E, Leiblum S, Luria M. Women's sexual desire and arousal disorders. J Sex Med. 2010 Jan;7(1 Pt 2):586-614. [PubMed] [CrossRef]

8. Goldmeier D, Bell C, Richardson D.
Withdrawal of selective serotonin reuptake imhibitors (SSRIs) may cayse increased atrial natriuretic peptide (ANP) and persistent sexual arousal in women? J Sex Med. 2006 Mar;3(2);376. [PubMed] [CrossRef]

9. Waldinger MD, de Lint GJ, Venema PL, van Gils AP, Schweitzer DH. Successful transcutaneous electrical nerve stimulation in two women with restless genital syndrome: The role of adelta- and C-nerve fibers. $J$ Sex Med. 2010 Mar;7(3):1190-9. [PubMed] [CrossRef]

10. Leiblum SR, Chivers ML. Normal and persistent genital arousal in women: New perspectives. J Sex Marital Ther. $2007 \mathrm{Jul}$;33(4):357-73. [PubMed] [CrossRef] 
11. Khan F, Spence VA, Kennedy G, Belch JJF. Prolonged acetylcholineinduced vasodilatation in the peripheral microcirculation of patients with chronic fatigue syndrome. Clin Physiol Func Imaging. 2003 Sep;23(5):282-5. [PubMed] [CrossRef]

12. Clayton A, Kornstein S, Prakash A, Mallinckrodt C, Wohlreich M. Changes in sexual functioning associated with doluxetine, esscitalopram and placebo in the treatment of patients with major depressive disorder. J Sex Med. 2007 Jul;4(4 Pt 1):917-29. [PubMed] [CrossRef]

13. Guiliano F, Rampin O, Allard J. Neurophysiology and pharmacology of female genital sexual response. $J$ Sex Marital Ther. 2002; 28(Suppl. 1):101121. [PubMed] [CrossRef]

14. Philippsohn S, Kruger TH. Persistent Genital Arousal Disorder: Successful Treatment with Duloxetine and Pregabalin in Two Cases. $J$ Sex Med. 2012 Jan;9(1):213-217. [PubMed] [CrossRef]

15. Korda JB, Pfaus JG, Goldstein I. Persistent Genital Arousal Disorder: A Case Report in a Woman with Lifelong PGAD Where Serendipitous Administration of Varenicline Tartrate Resulted in Symptomatic Improvement. J Sex Med. 2009 May;6(5):1479-1486. [PubMed] [CrossRef]

Address for correspondence

Assoc. prof. Mariana Arnaoudova, MD, PhD

MHAT 'St. Marina",

1, Hr. Smirnenski str., Varna 9010, Bulgaria

phone: 00359888512627

e-mail:marnaudova@hotmail.com; 